\section{Minocycline exerts a neuroprotective action against 6-OHDA-induced neurotoxicity: in vivo and in vitro studies}

\section{Abstract}

Background: Parkinson's disease (PD) is a chronic neurological disorder characterized by the loss of dopaminergic neurons in the substantia nigra pars compacta. The oxidative stress and inflammation, among other factors, are involved in the mechanisms of cell death in PD. We studied the neuroprotective properties of minocycline (Mino), focusing on its behavioral, neurochemical and immunohistochemical effects. Besides, Mino effects were also studied on an in vitro model of PD, as well as on the release of MPO in human neutrophils, and also its antioxidant activity.

Methods: We used in vivo (unilateral injection of 6-OHDA into the right striatum) and in vitro (SH-SY5Y cells) models of PD. For the in vivo model, male Wistar rats were divided into the following groups: sham-operated (SO), 6-OHDA-lesioned and untreated and 6-OHDAlesioned and treated with Mino (10 and 25 mg/kg, p.o., 7 days). The animals were evaluated for behavioral, neurochemical and immunohistochemistry alterations. We also focused on Mino cytoprotective effects, as evaluated by its antioxidant and anti-inflammatory effects (nitrite determination and MPO release).

Results: Mino (10 and $25 \mathrm{mg} / \mathrm{kg}$, p.o.) significantly reversed the decrease in striatal DA and DOPAC contents, the alteration in apomorphine-induced rotational behavior and the locomotor activity observed in 6-OHDA-lesioned rats, indicative of neuroprotection. Besides, it decreased the immunoreactivity for TNF-alpha in the hippocampus. In SH-SY5Y cells, Mino increased cells viability, as evaluated by the MTT assay, and significantly decreased the high nitrite levels observed
Pollyanna Landim Falcão Tavares Ferreira', Igor Pessoa Xavier ${ }^{1}$, Ítalo Roney Holanda ${ }^{1}$, Emílio Crisóstomo Limaverde', Gilvando Carneiro Leal Filho ${ }^{1}$, Hélio Vitoriano Nobre-Júnior ${ }^{2}$, Geanne Matos de Andrade2, Luzia Kalyne A. M. Leal' ${ }^{2}$, Glauce Socorro de Barros Viana $^{1,2}$

1 Faculty of Medicine Estácio of Juazeiro do Norte - FMJ, Av. Tenente Raimundo Rocha 515, Juazeiro do Norte, 63048080.

2 Faculty of Medicine, Federal University of Ceará, Rua Cel. Nunes de Melo 1127, Fortaleza, 60430-270, Brazil

Corresponding author:

”g gbviana@live.com

\section{Dr. Glauce Viana}

Rua Barbosa de Freitas, 130/1100. Fortaleza, 60170-020, Brazil 
in the cells after 6-OHDA-induced cytotoxicity. Mino presented antiinflammatory and antioxidant effects as evaluated by inhibition of MPO release (an inflammatory marker) on human neutrophils and DPPH assay.

Conclusion: Minocycline exerts neuroprotective effects in vivo and in vitro, decreasing dopaminergic cell loss, through mechanisms that are a consequence of Mino anti-inflammatory and antioxidant properties, pointing out to its potential application for the treatment of neurodegenerative diseases as PD.

Key Words: Minocycline, neuroprotection, Parkinson's disease, inflammation, oxidative stress.

\section{Introduction}

Parkinson's disease (PD) is a progressive neurodegenerative disorder characterized by loss of dopaminergic (DA) neurons in the substantia nigra pars compacta. The impaired production and secretion of dopamine cause symptoms, including bradykinesia, tremor, rigidity and other motor and cognitive problems [1]. PD is a common neurodegenerative disorder, associated with substantial morbidity, increased mortality and high economic burden [2].

A major problem in PD is the complexity of its onset. Pathways including protein aggregation, defects in the ubiquitin-proteasome system, mitochondrial damage, and oxidative and nitrosative stresses can contribute to the loss of dopaminergic neurons [3]. While different mechanisms, including environmental toxins and genetic factors initiate neuronal damage in the substantia nigra and striatum of PD patients, there is evidence that the activation of neuroinflammatory cells aggravates this neurodegenerative process [4]. Furthermore, inflammation is a neuropathological feature of parkinsonian brains and of experimental models of the disease.
Besides, activated glial cells contribute to the neurodegenerative process, through the production of toxic molecules [5].

Evidences have indicated that, in both patients and experimental models of PD, neuroinflammation appears as a ubiquitous finding [6]. Furthermore, the immunohistochemical demonstration of reactive microglia and activated components suggests that chronic inflammation occurs in PD brain regions, and the involvement of neuroinflammatory processes in nigral degeneration has gained attention [7].

Post-mortem examination of human subjects exposed to MPTP revealed the presence of activated microglia, decades after drug exposure, suggesting that even a brief pathogenic insult can induce an inflammatory response [8]. The iNOS expression was shown to be up-regulated in the substantia nigra of PD patients, but not of age-matched controls [9], suggesting that glial activation and the resulting release of NO may contribute to the chronic neurodegeneration that characterizes PD. The neurotoxin 6-hydroxydopamine (6-OHDA), similarly to MPTP, is largely used as a model of PD. It is known to 
cause inhibition of the mitochondrial complex I and oxidative stress, formed via DA oxidation [10, 11]. However, the exact mechanism by which 6-OHDA elicits its neurotoxic effects is not fully elucidated, although studies implicate a role for oxidative mediators $[12,13]$.

Minocycline (Mino) is a tetracycline exerting antiinflammatory effects, distinct from its antimicrobial action [14]. The drug is known to protect against brain ischemia $[15,16]$ associated with reduced activation in microglia and inhibition of induction of the IL-1beta-converting enzyme (ICE) m-RNA. This suggests that Mino may function by reducing cytotoxic properties of microglia, triggered either by ischemia or by excitotoxicity [17]. In addition, Mino inhibits MMP, superoxide production from neutrophils, and iNOS expression in human cartilages and murine macrophages [18, 19, 20].

The objectives of the present study were to investigate the neuroprotective action of Mino on a 6-OHDA-induced model of PD in rats. The focus was on behavioral alterations in untreated and Mino-treated 6-OHDA-lesioned animals, on measurements of striatal levels of DA and its metabolite DOPAC, as well as immunohistochemistry assays for TNF-alpha in the hippocampus. Besides, the effects of Mino on cell viability and nitrite concentrations in SH-SY5Y cells, on the release of MPO (an inflammation marker) from human-stimulated neutrophils, and the DPPH assay for antioxidant activities were also investigated.

\section{Materials and Methods}

\section{Drugs and Reagents}

6-Hydroxydopamine hydrochloride (6-OHDA), apomorphine and standard monoamines were purchased from Sigma, USA. Minocycline was from Ga- lena Laboratories, São Paulo, Brazil. Ketamine was purchased from König Laboratories (Buenos Aires, Argentina) and xylazine from Vetbrands Laboratory (São Paulo, Brazil). All other reagents were of analytical grade.

\section{Animals}

Adult male Wistar rats (260-280 g) from the Animal House of the Faculty of Medicine Estácio of Juazeiro do Norte (FMJ) were kept on a 12 h light/12 h dark cycle, with free access to water and standard food. All experiments were performed according to the Guide for the Care and Use of Laboratory Animals, from the US Health and Human Services Department. The protocol was approved by the Ethics Committee on Animal Experimentation, of the Faculty of Medicine Estácio of Juazeiro do Norte, Brazil.

\section{In vivo studies: experimental protocol and behavioral tests}

The animals were anesthetized with ketamine (30 $\mathrm{mg} / \mathrm{kg}$, i.p.) and xylazine (25 mg/kg, i.p.), and received two unilateral stereotaxic injections of $12 \mu \mathrm{g} /$ $\mu \mathrm{L}$ 6-OHDA each, containing $0.2 \mathrm{mg} / \mathrm{mL} \mathrm{L}$-ascorbic acid, into the right striatum, according to the following coordinates starting from bregma [21]: AP 0.5/0.9, LL 2.5/2.7, DV 5.0/6.5. Sham-operated (SO) animals received vehicle, and were used as controls. The treatment with Mino (10 and $25 \mathrm{mg} / \mathrm{kg}$, i.p.) started $1 \mathrm{~h}$ before the stereotaxic surgery (after the 6-OHDA-induced lesion), and continued daily for 7 days. Two weeks after the 6-OHDA injection, the behavior was assessed by monitoring body rotations induced by apomorphine (1 $\mathrm{mg} / \mathrm{kg}$, s.c.) when the number of net rotations (the number of $360^{\circ}$ contralateral turns) was recorded for $60 \mathrm{~min}$. The unilateral destruction of dopaminergic neurons causes a chemical imbalance of the brain content of this neurotransmitter. Because of this asymmetry, the administration of a dopamine agonist as apomor- 
phine causes stimulation of intact dopamine neurons in the unaffected brain hemisphere. This is behaviorally manifested by locomotion in the direction of the unaffected hemisphere, making the animal to run in circles. The quantification of circling behavior is used to access the efficacy of drugs potentially useful for the treatment of PD [22].

The animals were also submitted to the open field test, in order to evaluate their locomotor activity (usually affected in experimental models of PD), and at the next day were sacrificed, the striatal tissue collected and stored at $-70^{\circ} \mathrm{C}$ until use.

\section{Monoamine levels determination}

For measurements of dopamine and its metabolite (3,4 dihydroxyphenylacetic acid - DOPAC), striata from both sides of 6-OHDA-lesioned (untreated or treated with Mino) and unlesioned sham-operated groups were used to prepare 10\% homogenates. Homogenates were sonicated in $0.1 \mathrm{M} \mathrm{HClO}_{4}$, for $30 \mathrm{~s}$, centrifuged at $4^{\circ} \mathrm{C}$ for $15 \mathrm{~min}$ at $15,000 \mathrm{rpm}$, and the supernatants were filtered $(0.2 \mu \mathrm{m}$, Millipore). Twenty-microliter samples were then injected into a high-performance liquid chromatography (HPLC) column. The mobile phase was 0.163 $\mathrm{M}$ citric acid, pH 3.0, containing 0.02 mM EDTA with $0.69 \mathrm{mM}$ sodium octanesulfonic acid (SOS), as an ion pairing reagent, $4 \% \mathrm{v} / \mathrm{v}$ acetonitrile and $1.7 \% \mathrm{v} / \mathrm{v}$ tetrahydrofuran. The monoamines were electrochemically detected, using an amperometric detector (Shimadzu, Japan), by oxidation on a glassy carbon electrode at $0.85 \mathrm{~V}$ relative to the $\mathrm{Ag}-\mathrm{AgCl}$ reference electrode. Their concentrations were determined by comparison with standards injected into the HPLC column at the day of experiment, and the values expressed as ng/mg tissue.

\section{Immunohistochemistry for TNF-alpha in the hippocampus}

Hippocampal slices from SO, untreated 6-OHDAlesioned and 6-OHDA-lesioned rats treated with Mino (10 and $25 \mathrm{mg} / \mathrm{kg}$ ) were washed three times with $0.05 \mathrm{M}$ Tris buffer (TB, pH 7.6). Then, the endogenous peroxidase was blocked with $3 \% \mathrm{H}_{2} \mathrm{O}_{2}$ in 10\% methanol in TB, for $15 \mathrm{~min}$. The slices were washed three times again with TB and pre-incubated with $5 \%$ normal goat serum (NGS), for 30 min in $0.3 \%$ Triton, followed by the incubation with the primary TNF-alpha antibody (diluted in 2\% NGS/TB), overnight at $4^{\circ} \mathrm{C}$, according to the manufacturer's instructions (Calbiochem, Nottingham, UK). Then, after three washings with TB, the slices were incubated with the secondary antibody (biotinylated goat anti-rabbit IgG, 1:200, DAKO) for 2 h, washed three times again with $\mathrm{TB}$, and revealed with $0.05 \%$ diaminobenzidine in $0.03 \% \mathrm{H}_{2} \mathrm{O}_{2}$, for 10 min. After a final washing with distilled water, the slices were mounted for microscopy examination.

\section{In vitro studies with SH-SY5Y dopaminergic cells: cell culture}

The SH-SY5Y cell line from human neuroblastoma has become a popular cell model for PD research, because this cell line possesses many characteristics of DAergic neurons. For example, these cells express tyrosine hydroxylase and dopamine-beta-hydroxylase, as well as the dopamine transporter [23]. The cells were cultivated in $25 \mathrm{~cm}^{2}$ culture flasks (from Corning, USA) with a $50 \mathrm{~mL}$ volume, in 1:1 DMEM/ F12 medium (Gibco, USA), containing 10\% bovine fetal sera and $1 \%$ penicillin/streptomycin. The cells were then maintained in the oven at $37^{\circ} \mathrm{C}$ and a $5 \% \mathrm{CO}_{2} / 95 \% \mathrm{O}_{2}$ atmosphere. The cell growth was followed by observation on an inverted microscope. 


\section{MTT Assay in SH-SY5Y cells}

Minocycline neuroprotection was evaluated by the MTT assay, based on the conversion of the (3-(4,5-dimethylthiazol-2-yl)-2,5-diphenyltetrazolium bromide (MTT) yellow salt to the blue formazan compound. This conversion only occurs in metabolically active and viable cells, by the action of the succinate dehydrogenase enzyme present in mitochondria. This permits the indirect quantification of the percentage of viable cells [24]. For the assay, monolayers of SH-SY5Y cells were plated in 96 wells, at a $0.7 \times 10^{5}$ cells $/ \mathrm{mL}$ density. The cells were cultured for 5 days and then Mino (at concentrations of 0.1, 1 and $10 \mu \mathrm{g} / \mathrm{mL}$, based on previous experiments) was added $1 \mathrm{~h}$ before 6 -OHDA (12.5 $\mu \mathrm{g} / \mathrm{mL})$. After $24 \mathrm{~h}$ incubation in the oven, at $37^{\circ} \mathrm{C}$ and a $5 \%$ $\mathrm{CO}_{2}, 95 \% \mathrm{O}_{2}$ atmosphere, the suspension of cells culture was centrifuged (1500 rpm/15 min) and the supernatant discarded. Then, $200 \mu \mathrm{L}$ of a 10\% MTT solution (in 1:1 DMEM/F12 medium) were added to each well, followed by incubation for $3 \mathrm{~h}$ and centrifugation (3000 rpm/10 min). The supernatant was again discarded, and the formazan blue pellet resuspended; in $150 \mu \mathrm{L}$ DMSO and shaken for 10 min until complete dissolution. The quantification of the reduced MTT salt was carried out with a plaque reader at $595 \mathrm{~nm}$.

\section{Nitrite determination in SH-SY5Y cells}

The Griess reagent provides a simple and well characterized colorimetric assay for nitrites, and nitrates that have been reduced to nitrites, with a 100 $\mathrm{nM}$ detection limit. After cells incubation, the nitrite concentration was determined by the method of Green et al., 1981 [25]. For this, $100 \mu \mathrm{L}$ Griess reagent ( $1 \%$ sulphanilamide/0.1\% N-(1-naphthyl)ethylenediamine hydrochloride/ $1 \% \quad \mathrm{H}_{3} \mathrm{PO}_{4} /$ distilled water, 1:1:1:1) were added to $100 \mu \mathrm{L}$ cell culture supernatant, followed by 10 min incubation at room temperature. The standard curve was made with concentrations of $\mathrm{NaNO}_{2}$, ranging from 0.75 to 100 $\mu \mathrm{M}$ under the same conditions. Blanks were prepared by the addition of $100 \mu \mathrm{L}$ Griess reagent to $100 \mu \mathrm{L}$ culture medium, and the absorbance determined with a plaque reader at $560 \mathrm{~nm}$.

\section{Myeloperoxidase release from human neutrophils}

Myeloperoxidase (MPO) is an enzyme stored in azurophilic granules of polymorphonuclear neutrophils and macrophages, and released into extracellular fluid in the setting of inflammatory process. It is involved in oxidative stress and inflammation, and thus considered as a marker for systemic inflammation. Following Lucisano and Mantovani, 1984 [26], $2.5 \times 10^{6}$ human leukocytes were suspended in buffered Hank's balanced salt solution, containing calcium and magnesium. The preparations usually contained predominantly neutrophils $(85.0 \pm$ $2.8 \%)$, and the cell viability, as determined by the Trypan blue test, was $97.7 \pm 0.94 \%$. The cells were incubated with Mino (0.001 to $1 \mu \mathrm{g} / \mathrm{mL}$ ) or indomethacin at $35.7 \mu \mathrm{g} / \mathrm{mL}$ (Indo, as standard), for 15 min at $37^{\circ} \mathrm{C}$. Human neutrophils were stimulated by the addition of phorbol myristate acetate (PMA, $0.1 \mu \mathrm{g} / \mathrm{mL}$ ), for $15 \mathrm{~min}$ at $37^{\circ} \mathrm{C}$. The suspension was centrifuged for $10 \mathrm{~min}$ at $2000 \times \mathrm{g}$ at $4^{\circ} \mathrm{C}$. Aliquots $(50 \mu \mathrm{L})$ of the supernatants were added to phosphate-buffered saline $(100 \mu \mathrm{L})$, phosphate buffer ( $50 \mu \mathrm{L}, \mathrm{pH} 7.0)$ and $\mathrm{H}_{2} \mathrm{O}_{2}(0.012 \%)$. After 5 min at $37^{\circ} \mathrm{C}$, TMB $(1.5 \mathrm{mM}, 20 \mu \mathrm{L})$ was added, and the reaction was stopped by $30 \mu \mathrm{L}$ sodium acetate (1.5 M, pH 3.0). The absorbance was determined using a spectrophotometer $(620 \mathrm{~nm})$

\section{Diphenyl-2-picriylhydrazyl (DPPH)-scavenging activity}

The stable free radical DPPH (2,2-diphenyl-1-picrylhydrazyl-hydrate) is used as an antioxidant assay, based on electron-transfer that produces a violet 
solution in ethanol. This free radical is reduced in the presence of an antioxidant molecule, giving rise to colorless ethanol solution. This assay provides an easy and rapid way to evaluate antioxidants by spectrophotometry. Minocycline and alpha-tocopherol (as reference) were evaluated by the DPPH assay [27]. Briefly, an aliquot $(0.1 \mathrm{~mL})$ of Mino (1 to $50 \mu \mathrm{g} /$ $\mathrm{mL}$ ) or alpha-tocopherol (5 or $50 \mu \mathrm{g} / \mathrm{mL}$ ) was mixed with $3.9 \mathrm{~mL}$ DPPH solution $(0.3 \mathrm{mM})$. The mixture was vortexed for 1 min and then left standing at room temperature for 30 min. Finally, the absorbance of the resulting solution was read spectrophotometrically (Beckman Instruments Inc.) at 517 nm.

\section{Statistical Analyses}

For monoamine contents, the data were analyzed by the Student's t test, when comparison was performed between right and left striata from the same group, and by One-way ANOVA followed by Newman-Keuls as a post hoc test, for comparing the same striatal side among groups. Identical procedure was used for all other statistical analyses.

\section{Results}

Effects of the minocycline (Mino) treatment on striatal DA and its metabolites in 6-OHDA-lesioned rats The 6-OHDA-lesioned right striata showed a 63\% decrease in DA concentrations, as compared to the unlesioned left striata of the same group. This decrease was lower in th 6-OHDA-lesioned right striata of Mino-treated rats, especially in the 6-OHDA+Mino25 group whose reduction was only $20 \%$, as compared to its left side. The SO group showed no change in DA content (Fig. 1A) The percentage reductions of DOPAC levels in the right striata of the 6-OHDA-lesioned group were around
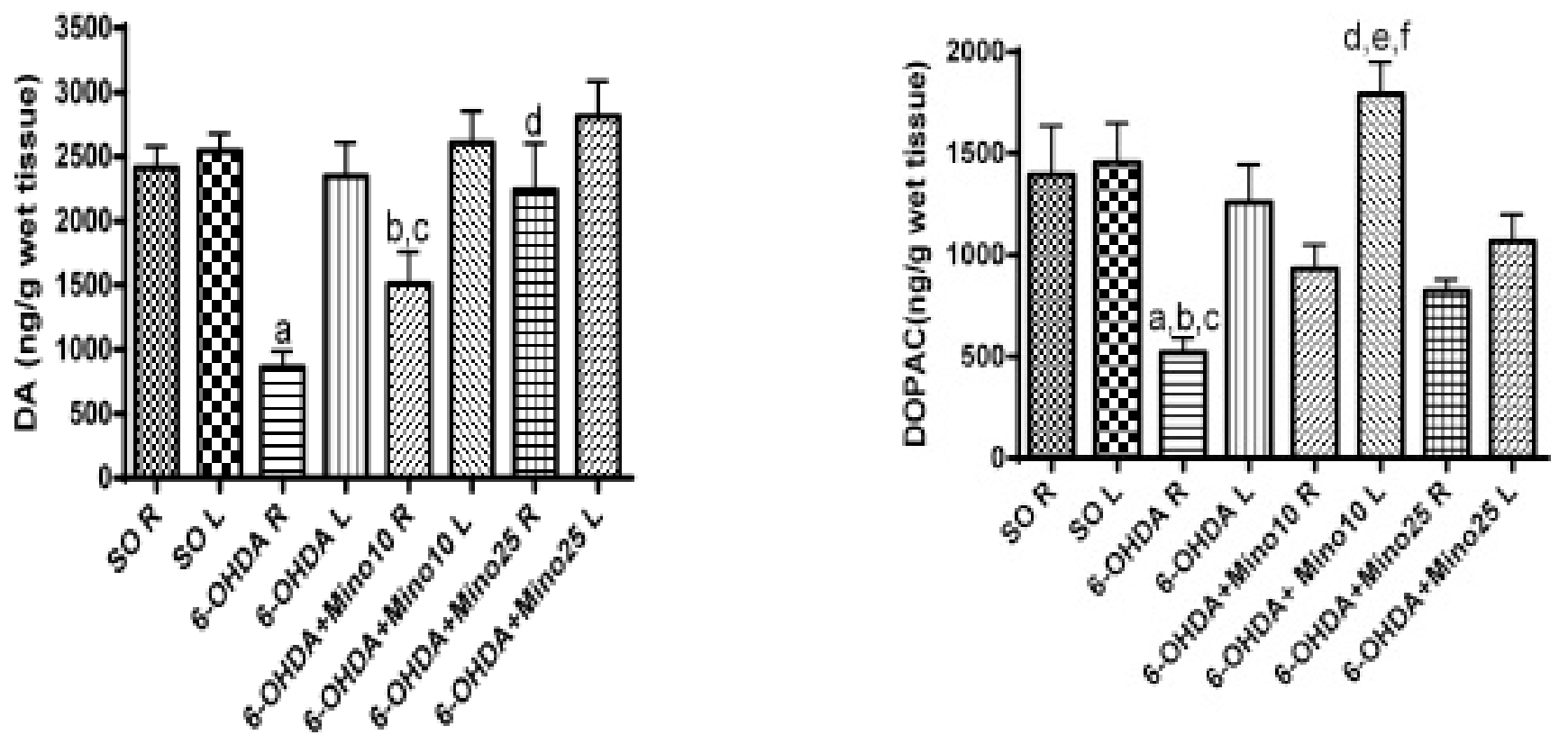

Figure 1. Minocycline (Mino: 10 and 25 mg/kg, i.p.) significantly reversed the DA (A) and DOPAC (B) contents in the lesioned right striatum $(R)$, as related to its unlesioned left side $(L)$ and mainly to the right side of the 6-OHDA-lesioned untreated group. The values are means \pm S.E.M. from 6 to 14 animals per group. $\mathrm{SO}=$ sham-operated group. (A): a. $p<0.001$ vs. 6-OHDA L; b. p $<0.05$ vs. 6 -OHDA R; c. p < 0.05 vs. $6-O H D A+$ Mino10 L; d. $p<0.001$ vs. $6-O H D A$ R. (B): a. $p<0.001$ vs. $6-O H D A$ L; b. $p<0.05$ vs. $6-0 H D A+$ Mino10 R; c. $p<0.05$

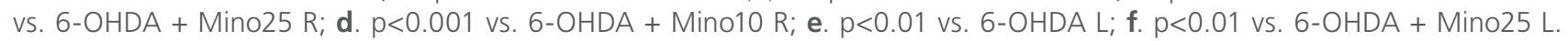




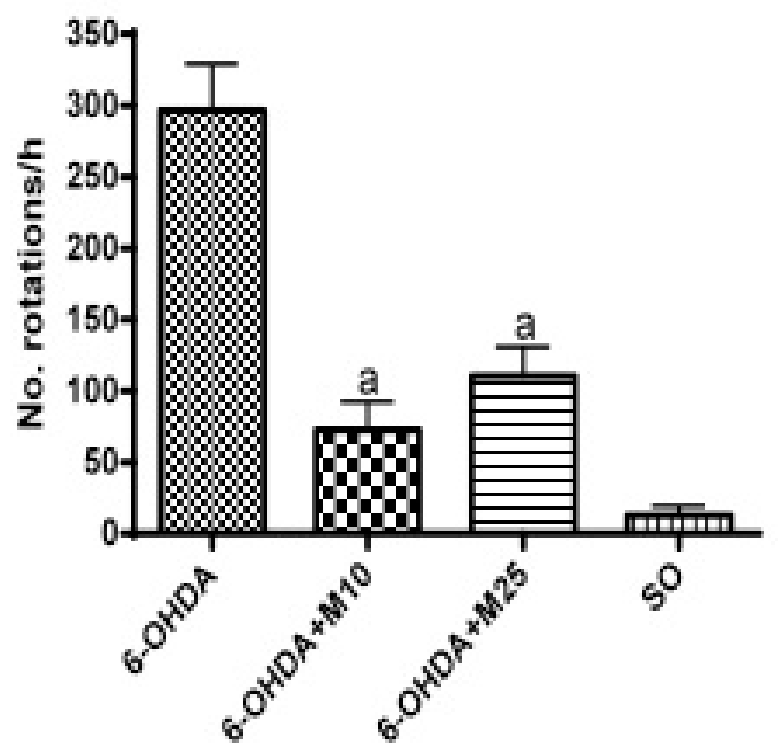

Figure 2. Minocycline (Mino: 10 and 25 mg/kg, i.p.) significantly reversed the increased apomorphine-induced rotational behavior, evaluated by the number of contralateral rotations for $1 \mathrm{~h}$, as compared to the 6-OHDA-lesioned untreated group. As expected, very few rotations were seen in the sham-operated (SO) group. The values are means \pm S.E.M. from 17 to 22 animals per group. a. $p$ $<0.001$ vs. $6-$ OHDA

$60 \%$, in relation to its unlesioned left side, while these changes were lower after Mino treatments (50 and 23\% decreases after the doses of 10 and $25 \mathrm{mg} / \mathrm{kg}$, respectively). No significant alterations in DOPAC contents were observed in either side of the striata in the SO group (Fig. 1B).

\section{Apomorphine-induced rotational behavior in 6-OHDA-lesioned rats, without and with minocycline treatments}

While 6-OHDA-lesioned and untreated rats presented high numbers of contralateral rotations (296.7 \pm 32.12 turns/h), this effect was significantly reversed after Mino treatments (6-OHDA+Mino10: 72.6 \pm 20.05 turns/h; 6-OHDA+Mino25: 110.5 \pm 20.20 turns/h). On the other hand, almost no rotation was shown by the SO group (12.8 \pm 6.53 turns/h) (Fig. 2).

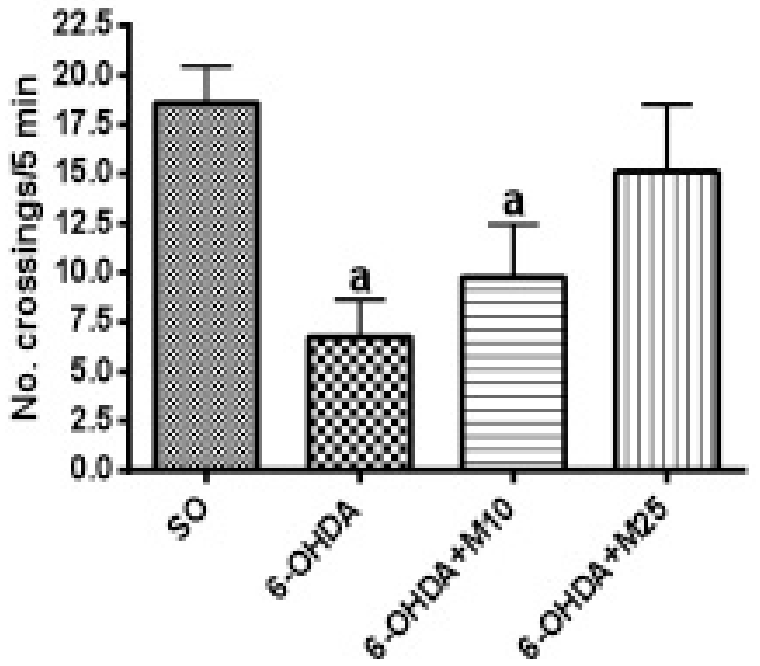

Figure 3. Minocycline (Mino: 10 and $25 \mathrm{mg} / \mathrm{kg}$, i.p.) partially reversed the decreased locomotor activity (number of crossings/5 min) observed in 6-OHDA-lesioned untreated rats. However, the locomotor activity was higher in the controls (sham-operated group = SO) but not statistically different from the 6-OHDA+Mino25 group. The values are means \pm S.E.M. from 7 to 10 animals per group. a. $p<0.05$ vs. SO.

\section{Exploratory behavior in the open field test}

The 6-OHDA-lesioned rats showed a significant decrease of $64 \%$ in locomotor activity $(6.7 \pm 1.92)$, compared to the SO group (18.6 \pm 1.85$)$, as evaluated by the number of crossings $/ 5 \mathrm{~min}$. The treatment of the 6-OHDA-lesioned group with the two doses of Mino reverted this effect, bringing values close to those of the SO group with the higher dose

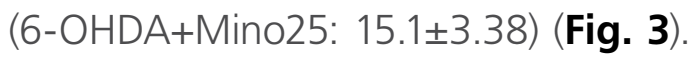

\section{Minocycline (Mino) decreases the immunoreactivity for TNF-alpha in the rat hippocampus}

Figure 4 shows representative photomicrographs of dentate gyrus where the untreated 6-OHDA-lesioned group presents a high immunoreactivity for TNF-alpha. This effect was in great part reversed by Mino treatments (6-OHDA+Mino 10 or 25). On the other hand, few immunopositive cells for TNF-alpha were seen in the SO group. 
Figure 4. Minocycline (10 and $25 \mathrm{mg} /$ $\mathrm{kg}$ ) decreases the number of TNF-alpha immunopositive cells in the hippocampus (dentate gyrus), as related to the untreated 6-OHDA-lesioned group. A: SO; B: untreated 6-OHDA; C: 6-OHDA+Mino10; D: 6-OHDA+Mino25 (200X magnification).
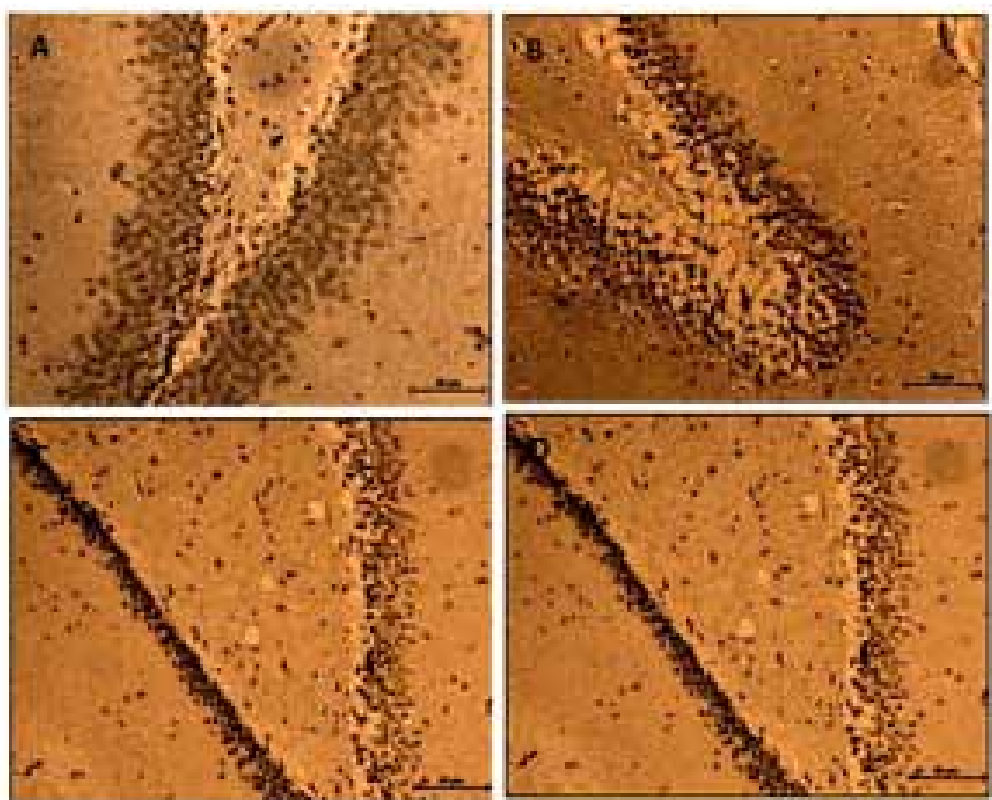
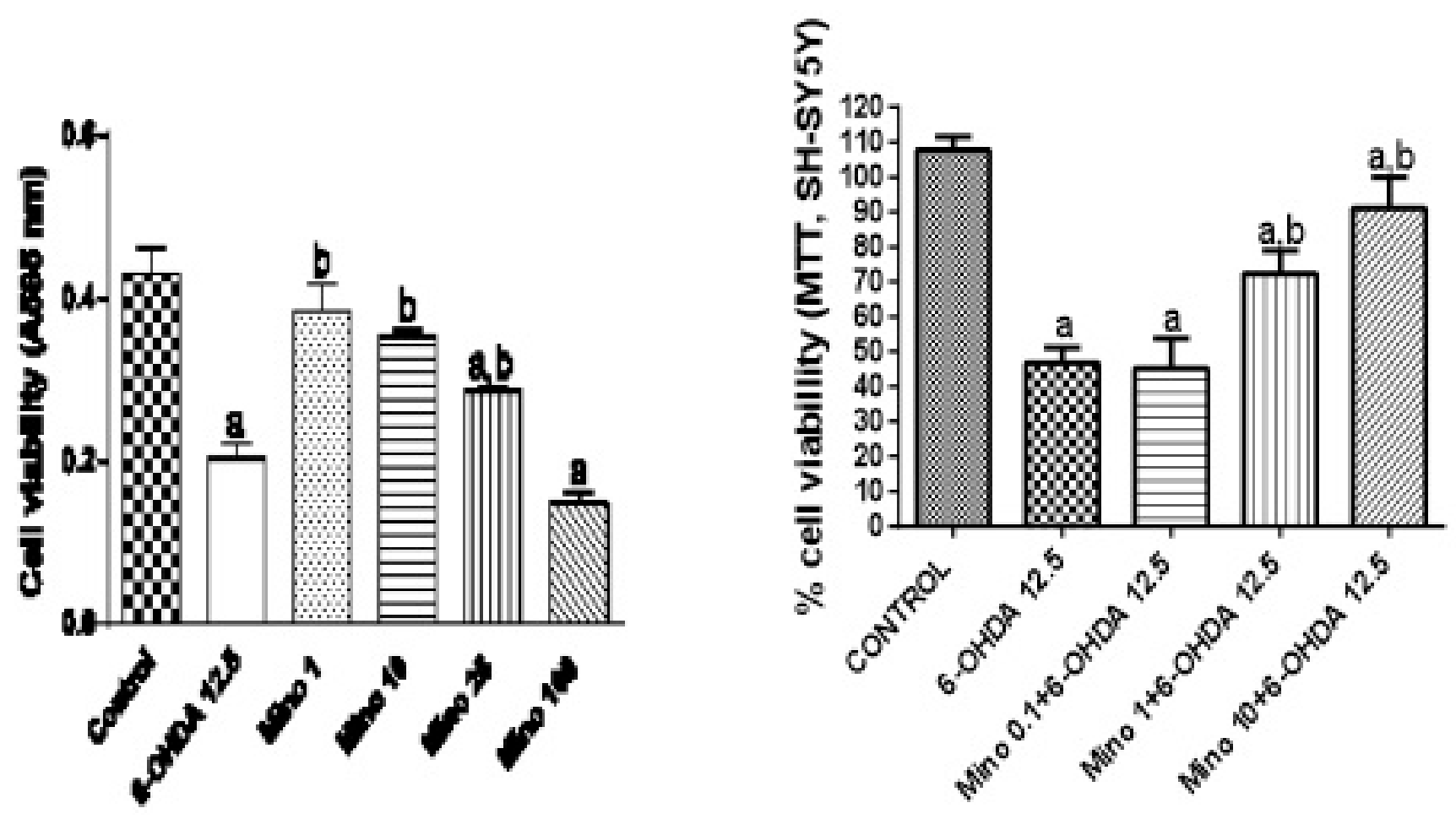

Figure 5. Concentration-response curve of minocycline (Mino: 1 to $100 \mu \mathrm{g} / \mathrm{mL}$ ) in SH-SY5Y cells, showing a cytotoxic effect at concentrations equal to or higher than $100 \mu \mathrm{g} / \mathrm{mL}$ (A). 6 -OHDA at the concentration of $12.5 \mu \mathrm{g} / \mathrm{mL}$ decreased cell viability by $64 \%$, as related to controls. The values are means \pm S.E.M. from 3 to 12 samples. a. $p<0.05$ to 0.001 vs. controls; $b$. $p<0.05$ to 0.01 vs. 6-OHDA 12.5. (B) Minocycline (Mino: 0.1, 1 and $10 \mu \mathrm{g} / \mathrm{mL}$ ) significantly and dose-dependently protected SH-SY5Y cells from death, after their exposure to the 6-OHDA neurotoxin $(12.5 \mu \mathrm{g} / \mathrm{mL})$, as evaluated by the MTT assay. While 6-OHDA decreased by $66 \%$ the percentage of cell viability, Mino partially blocked the neurotoxin effect, bringing values closer to those of controls. $a . p<0.001$ vs. controls; $b . p<0.05$ vs. $6-0$ HDA 12.5 . 


\section{In vitro studies}

\section{Effects of minocycline on cell viability, as evaluated by the MTT assay in SH-SY5Y cells}

Fig. 5A shows the Mino concentration-response curve, demonstrating that it decreases cells viability at concentrations equal or higher than $100 \mu \mathrm{g} /$ $\mathrm{mL}$, an indicative of cytotoxicity. A 57\% decrease was observed in SH-SY5Y cells viability, after their exposure to the 6 -OHDA neurotoxin $(12.5 \mu \mathrm{M})$, as related to the untreated cells (controls). The cell treatment with Mino $(0.1,1$ and $10 \mu \mathrm{g} / \mathrm{mL}$ ) partially reversed the neurotoxin effect, improving cells viability which decreased by only 33 and $15 \%$ with Mino, at the concentrations of 1 and $10 \mu \mathrm{g} / \mathrm{mL}$, respectively. The lower dose $(0.1 \mathrm{\mu g} / \mathrm{mL})$ showed no cytoprotective effect (Fig. 5B).

\section{Effects of minocycline on nitrite concentrations in SH-SY5Y cells}

The SH-SY5Y cells exposure to 6-OHDA $(12.5 \mu \mathrm{M})$ significantly increased the nitrite concentration by sixfold, as compared to the unexposed cells (controls). On the other hand, this neurotoxin effect was almost completely reversed after the addition of Mino, at concentrations of $0.1,1$ and $10 \mu \mathrm{g} / \mathrm{mL}$. Under these conditions, the nitrite concentrations increased only from 1.5- to 1.9-fold (Fig. 6).

\section{Minocycline inhibits MPO release in human neutrophils}

Figure 7 shows a concentration-dependent effect of Mino on MPO release by human neutrophils. While only $8 \%$ inhibition was achieved in the presence of Mino, at $0.001 \mu \mathrm{g} / \mathrm{mL}$, the percentage inhibition increased to almost $70 \%$, at the concen-

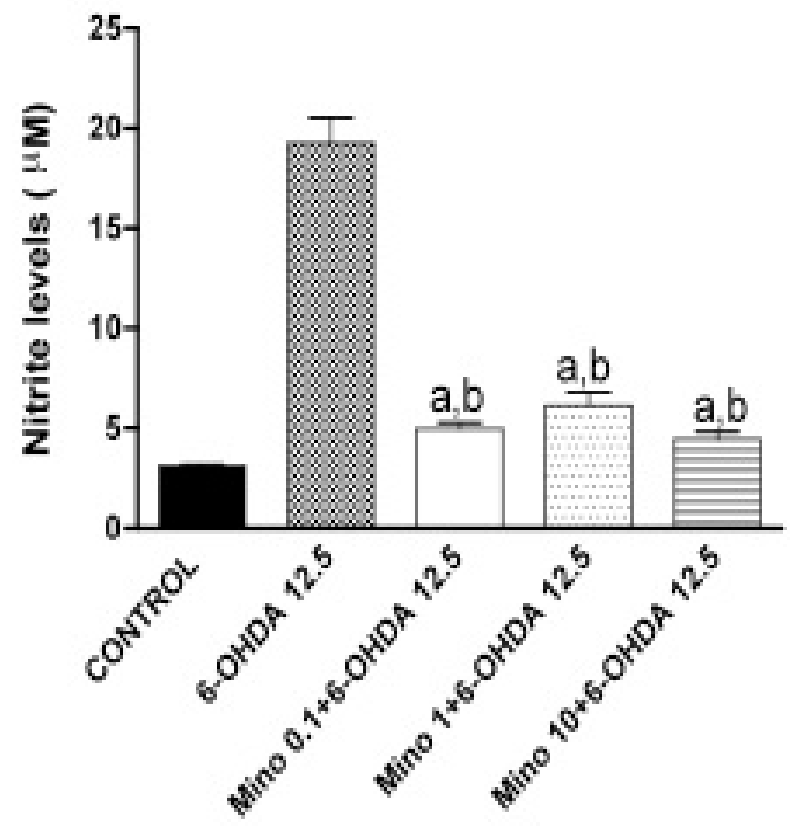

Figure 6. Minocycline (Mino: 0.1, 1 and $10 \mu \mathrm{g} / \mathrm{mL}$ ) completely reversed the increased nitrite levels observed in SH-SY5Y cells, after their exposure to 6-OHDA, and the values (means \pm S.E.M. from 4 to 15 samples) were very close to those of controls. a. $p<0.05$ vs. controls; b. $p<0.001$ vs. 6 -OHDA 12.5

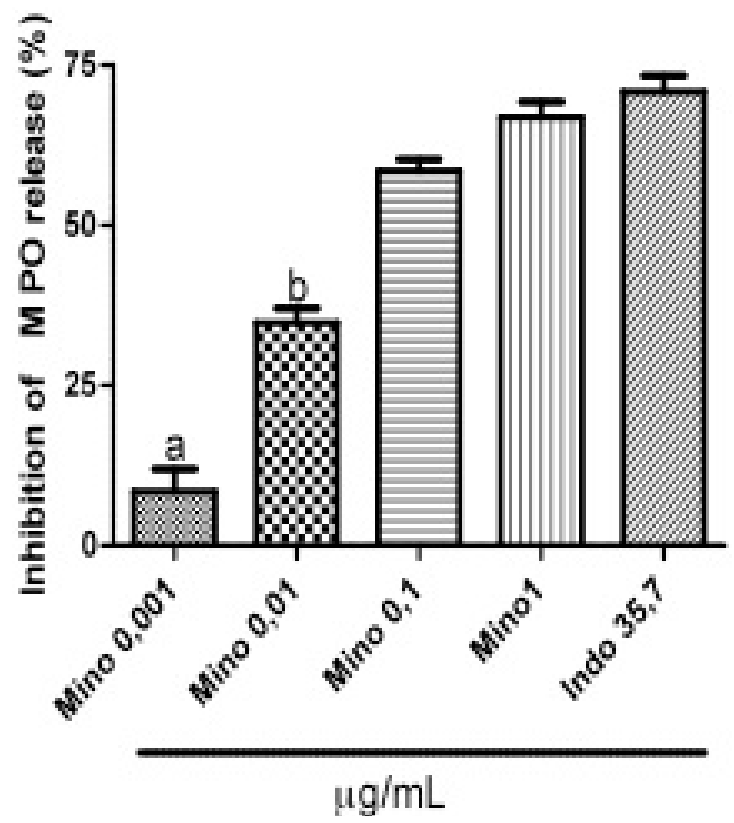

Figure 7. Minocycline $(\mu \mathrm{g} / \mathrm{mL}$ ) inhibits the myeloperoxidase (MPO) release from human neutrophils, at $1 \mu \mathrm{g} / \mathrm{mL}$ concentration, and this effect was similar to that observed in the presence of indomethacin (Indo, $35.7 \mu \mathrm{g} / \mathrm{mL}$ ) used as reference. Assays were performed in at least quadruplicated samples. a. and b. vs. all other four groups, $p<0.0001$. 


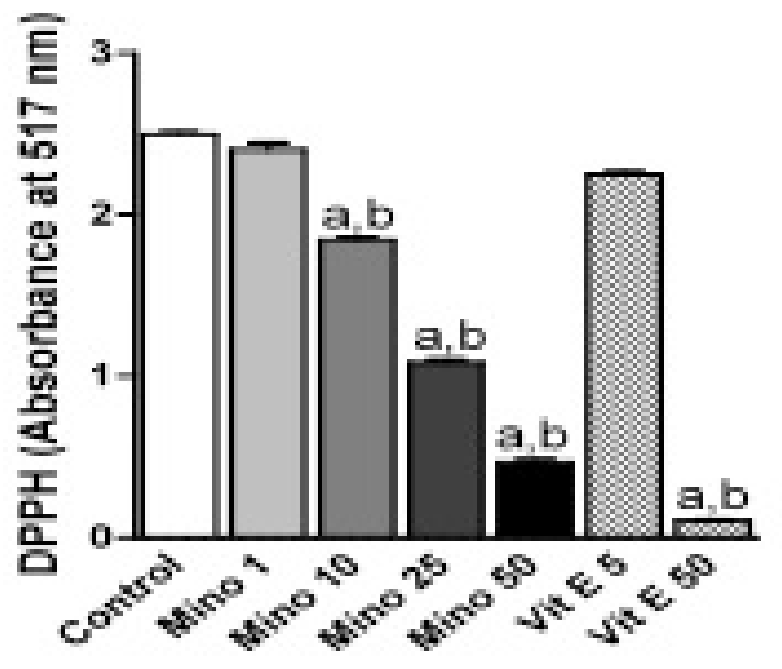

Figure 8. Minocycline $(\mu \mathrm{g} / \mathrm{mL})$ presents a radical scavenger activity, as evaluated by the DPPH assay. A significant effect was observed at a concentration of $50 \mu \mathrm{g} / \mathrm{mL}$, similar to that observed in the presence of vitamin $\mathrm{E}$ used as reference. Assays were performed at least in quadruplicated samples. a. and b. $p<0.0001$ vs. controls and Vitamin E 50

tration of $1 \mu \mathrm{g} / \mathrm{mL}$. This value was similar to that observed in the presence of indomethacin (Indo, $35.7 \mu \mathrm{g} / \mathrm{mL}$ ), used as reference.

\section{Scavenging activity of minocycline, as evaluated by the DPPH assay}

Data on the antioxidant effect of Mino, at concentrations ranging from 1 to $50 \mu \mathrm{g} / \mathrm{mL}$, are shown in Fig. 8. In this assay, a significant effect of Mino was observed only with the concentration of $50 \mu \mathrm{g} / \mathrm{mL}$, comparable to that observed in the presence of vitamin $\mathrm{E}$ (used as reference), at a similar concentration.

\section{Discussion}

Our data demonstrated that minocycline (Mino) can effectively protect striatal dopaminergic neurons from the effects of the 6-OHDA neurotoxin, in rats which is a widely used model for Parkinson's disease. The neuroprotective effect of Mino (10 and $25 \mathrm{mg} / \mathrm{kg}$ ) was observed after its intraperitoneal administration for 7 days. Although there are many studies showing the neuroprotective effects of Mino on various experimental models, such as cerebral ischemia $[28,29,30,31]$ among others, those on PD models are fewer [32, 33].

We showed, in the model of unilateral striatal $6-\mathrm{OH}-$ DA-lesioned rats, that the increased apomorphineinduced rotation turns were significantly decreased by Mino, indicative of a neuroprotective effect and less degeneration of dopaminergic neurons. The unilateral injection of 6-hydroxydopamine (6OHDA) into the right substantia nigra or striatum is known to produce an extensive loss of dopaminergic cells. The imbalance in dopaminergic innervation between both sides results in a postural asymmetry, causing rotation away from the contralateral unlesioned side. Analyses of mitochondrial oxidative phosphorylation enzyme activities, in nigral tissue from 6-OHDA-lesioned rats, revealed a clear loss of complex I activity [34]. A deficit in mitochondrial complex I could conceivably contribute to cell death in parkinsonism, via free radical mechanisms, both directly by reactive oxygen species production and indirectly by the decreased ATP synthesis and energy failure.

Additionally, we showed that 6-OHDA significantly reduced DA contents in the lesioned right striatum, as compared to the unlesioned left striatum of the same experimental group. Mino treatments reversed the decreases in DA contents in the lesioned right striatum, compared to the 6-OHDA-lesioned right striatum of untreated rats, also suggesting that the drug presents a neuroprotective effect. A similar result was observed in DOPAC contents.

The toxicity of 6 -OHDA seems to be related to the production of ROS, including superoxide radicals, 
hydrogen peroxide and hydroxyl radicals [35, 36, 37]. The pronounced toxicity on DA neurons is due to the selective uptake of this toxin by the DA transporter (DAT) system, as well as the presence of monoamine oxidase (MAO) and low tolerance of the dopaminergic neuronal population to oxidative stress. Indeed, ROS and the oxidative stress have been pointed out as key factors in the pathogenic cascade, leading to loss of midbrain DA neurons in PD [38].

The intra-striatal administration of 6-OHDA has been found to induce a microglial reaction [39] that may participate in the progression or extension of neuronal loss caused by the neurotoxin. Minocycline was demonstrated to protect nigral cells from MPTP and 6-OHDA toxicities [40]. This antibiotic (45 $\mathrm{mg} / \mathrm{kg}$, i.p.) displayed beneficial effects against the striatal injection of 6-OHDA, and the subsequent nigral cell degeneration and microgliosis. Protection against this toxin has been also observed in vitro (41). The oral administration of Mino (60-120 $\mathrm{mg} / \mathrm{kg}$, p.o., or 11-45 mg/kg, i.p.) blocked MPTPinduced degeneration of dopamine neurons, as well as the loss of striatal dopamine and its metabolites, and mitigated the formation of nitrotyrosine. These effects were thought to be related to an inhibitory effect of Mino on microglial activation (42).

Almost all the beneficial effects of Mino are related to an inhibitory activity on inflammation processes and/or apoptotic cell death, both phenomena being intimately related to neuronal degeneration [43]. Interestingly, Mino also protected dopaminergic neurons from the activation of microglia, induced by an injection of lipopolysaccharide (LPS) within the substantia nigra [44]. Accordingly, several studies showed that Mino reduces the expression of inducible nitric oxide synthase and subsequent nitric oxide production, as well as caspase-1 activity/ expression, and thereby prevents the formation of IL-1beta $[45,46]$.
Mino also prevents oxidative protein modifications and damage in disease models associated with inflammatory glial activation and oxidative stress and, although the drug is assumed to act by preventing the up-regulation of pro-inflammatory enzymes, it has been shown that Mino acts by a direct chemical interaction with ROS [47]. Others suggested that the neuroprotective effects of Mino might be associated with the mitigation of neuronal excitability, glutamate release and $\mathrm{Ca}^{2+}$ overloading [48].

We showed that decreased locomotor activity observed in hemiparkinsonian rats was reversed after Mino treatment. A similar effect was seen in grooming behavior. Previously, we demonstrated that ischemia-induced behavior alterations were reversed by Mino, and in this case all the observed parameters (locomotor activity, rearing and grooming behaviors) were equally affected [49]. It has been found that Mino, administered to mice after traumatic brain injury (TBI), attenuated microglial activation and reduced the brain lesion volume, as well as TBI-induced hyperactivity [50].

Chronic neuroinflammation is a typical feature in neurodegenerative diseases, including $P D$, in which TNF-alpha expression appears to be upregulated representing a valuable target for intervention [51, 52, 53]. In addition, evidences indicate that TNFalpha may play a role in the selective vulnerability of the nigrostriatal pathway associated to dopaminergic neurotoxicity [54]. Minocycline is known to protect cells, via an anti-inflammatory mechanism [55], and a recent study demonstrated that it decreased brain TNF-alpha levels, as evaluated by a hypothermic cardiac arrest model in rats [56].

We showed a decreased immunoreactivity for TNFalpha in the hippocampus from 6-OHDA-lesioned rats after treatments with Mino, as related to the 6-OHDA-lesioned and untreated group. Neuropathological studies show that the hippocampus 
is affected in PD, and hippocampal degeneration could be responsible for the patient's cognitive dysfunction [57]. Moreover, other data suggest interactions between the dopaminergic system and hippocampus, in synaptic plasticity, adaptive memory and motivated behavior [58], and that the declarative memory impairment in PD patients without dementia may be predicted by the rate of microstructural alterations in the hippocampal formation [59]. Our findings may certainly contribute to the drug neuroprotective action.

We also demonstrated that Mino protected $\mathrm{SH}$ SY5Y cells against 6-OHDA cytotoxicity in a dosedependent manner, as evaluated by the MTT assay. As a matter of fact, the drug seems to exhibit a toxic action, at concentrations equal to or higher than a $100 \mu \mathrm{g} / \mathrm{ml}$. Furthermore, Mino significantly decreased nitrite contents of cells previously exposed to 6-OHDA, indicating an antioxidant action. SHSY5Y cells are originated from human neuroblastoma and known to mimic many aspects of the dopaminergic neuronal death observed in PD, caused by mitochondrial complex I neurotoxins $[23,49$. 50]. The SH-SY5Y cell line has become a popular model for PD, for possessing many characteristic of dopaminergic neurons. Thus, these cells express tyrosine hydroxylase and dopamine- $\beta$ hydroxylase, as well as the dopamine transporter (DAT).

Although it is accepted that 6-OHDA induces cytotoxicity in different cell types, the mechanisms involved are controversial, and among them the generation of ROS is the most accepted one [42, $60,61]$. Thus, 6-OHDA can either undergo extracellular auto-oxidation or intracellular enzymatic oxidation through MAO B, yielding ROS, quinones and their degradation products [62]. It has been found that 6-OHDA induces mitochondrial fragmentation in SH-SY5Y cells [63]. These authors showed that 6-OHDA-induced mitochondrial fragmentation is an early event, preceding the collapse of the mem- brane potential and cytochrome c release in $\mathrm{SH}$ SY5Y cells.

Minocycline was shown to inhibit iNOS expression and NO release, and to increase neuronal survival, as well as to inhibit the production of TNF-alpha mediated by LPS in glial cells [64]. These authors used Mino concentrations ranging from 1 to $20 \mathrm{nM}$, and found a maximal neuroprotective effect without toxicity, at the concentration of $1 \mathrm{nM}$.

Minocycline was able to significantly decrease the myeloperoxidase release from human neurotrophils, at very low concentrations $(0.1 \mu \mathrm{g} / \mathrm{mL})$, and its effect was similar to that of indomethacin used as reference. Myeloperoxidase (MPO) is a hemoprotein abundantly expressed in polymorphonuclear leukocytes (neutrophils) and secreted during their activation. This enzyme has been proposed as a biomarker of inflammation, under several pathological conditions [65, 66, 67]. In addition, Mino presented an antioxidant activity in vitro, as evaluated by the DPPH assay.

Increasing evidence [68] indicates that both oxidative stress and inflammation may play a fundamental role in the pathogenesis of PD, and minocycline was shown to prevent oxidative protein modifications and damage in disease models associated with inflammatory glial activation and oxidative stress [69]. Previously, we demonstrated a potent anti-inflammatory effect of Mino acutely administered in several models of inflammation [70]. In addition, Mino sub-chronically injected significantly reversed neurochemical and behavior alterations, in models of global ischemia and PD in rats [71]. Our data indicate that the anti-inflammatory and antioxidant effects, besides the inhibitions of iNOS and TNF-alpha among other properties, could stimulate translational data from experimental studies to randomized and well-designed clinical trials of neuroprotective agents as Mino, for new therapeutic 
applications, especially those where inflammation plays a role [72]. We conclude that Mino may act as a dopaminergic agonist, and this effect together with the drug anti-inflammatory and antioxidant activities are probably responsible for its neuroprotective action.

\section{Acknowledgments}

The study had the financial support from the Brazilian National Research Council (CNPq). The authors thank Ms. Xenia Maria Sousa Serra and Ms. M.Vilani Rodrigues Bastos for the technical assistance, and Prof. M.O.L. Viana for the orthographic revision of the manuscript. 


\section{References}

1. DeSantis, ME., Dersh, D. Preventing Parkinson's pathology. Disease Models \& Mechanisms 2010; 3: 399-400.

2. Weintraub, D., Comella, CL., Horn, S. Parkinson's disease. Part 1: Pathophysiology, symptoms, burden, diagnosis, and assessment. Am J Manag Care 2008; 14: S40-S48.

3. Dawson, TM., Dawson, VL. Molecular pathways of neurodegeneration in Parkinson's disease. Science 2003; 313: 324-328.

4. Wilms, H., Zecca, L., Rosenstiel, P., Sievers, J., Deuschl, G., Lucius, R. Inflammation in Parkinsons's disease and other neurodegenerative diseases: cause and therapeutic implications. Curr Pharm Des 2007; 13: 1925-1928.

5. Przedborski, S. Inflammation and Parkinson's disease pathogenesis. Movement Disorders 2010; 25: S55-S57.

6. Whitton, PS. Inflammation as a causative factor in the aetiology of Parkinson's disease. Brit J Pharmacol 2007; 150: 963-976.

7. Mcgeer, PL., McGeer, EG. Inflammation and neurodegeneration in Parkinson's disease. Parkinsonism Relat Disord 2004; Suppl. 1: 53-7.

8. Hald, A., Lotharius, J. Oxidative stress and inflammation in Parkinson's disease: Is there a causual link? Exp. Neurol. 2005; 193: 279-290.

9. Hunot, S., Boissiere, F., Faucheux, B., Brugg, B., Mouatt-Prigent, A., Agid, Y., Hirsch, EC. Nitric oxide synthase and neuronal vulnerability in Parkinson's disease. Neuroscience 1996; 72: 355363.

10. Soto-Otero, R., Méndez-Álvarez, E., Hermida-Ameijeiras, A., Múñoz-Patiño, A., Labandeira-García, JL. Autooxidation and Neurotoxicity of 6-Hidroxydopamine in the presence of some antioxidants: Potential implication in the relation to pathogenesis of Parkinson's disease. Journal of Neurochemistry 2000; 74 (4): 1605-1612.

11. Jellinger, K., Linert, L., Kienzl, E., Herlinger, E., Youdin, MB. Chemical evidence for 6 -hydroxydopamine to be an endogenous toxic factor in the pathogenesis of Parkinson's disease. J Neurol Transm 1995; Suppl. 46: 297-314.

12. Glinka, YY., Youdin, MB. Inhibition of mitochondrial complexes I and IV by 6-hydroxydopamine. Eur J Pharmacol 1995; 292: 329332.

13. Asanuma, M., Hirata, H., Cadet, JL. Attenuation of 6-hydroxydopamine-induced dopaminergic nigroestriatal lesions in superoxide dismutase transgenic mice. J. Neuroscience 1998; 85: 907-917.

14. Ryan, ME., Ashley, RA. How do tetracyclines work? Adv Dent Res 1998; 12: 149-151.

15. Yrjãnheikki, J., Keinanen, R., Pellikka, M., Hokfelt, T., Koistinaho, J. Tetracyclines inhibit microglial activation and are neuroprotective in global brain ischemia. Proc Nat Acad Sci USA 1998; 95 (26): 15769-15774.
16. Yrjãnheikki, J., Tikka, T., Keinanen, R., Goldsteins, G., Chan, PH., Koistinaho, J. A tetracycline derivative, minocycline, reduces inflammation and protects against focal cerebral ischemia with a wide therapeutic window. Proc Nat Acad Sci USA 1999; 96 (23): 13496-13500.

17.Tikka, T., Fiebich, BL., Goldsteins, G., Keinanen, R., Koistinaho, J. Minocycline, a tetracycline derivative, is neuroprotective against excitotoxicity by inhibiting activation and proliferation of microglia. J Neuroscience 2001; 21: 2580-2588.

18. Golub, LM., Lee, HM., Ryan, ME., Giannobile, WV., Payne, J., Sorsa, T. Tetracyclines inhibit connective tissue breakdown by multiple non-antimicrobial mechanisms. Adv Dent Res 1998; 12 (2): 12-26.

19. Gabler, WL., Smith, J., Tsukuda, N. Comparison of doxycycline and a chemically modified tetracycline inhibition of leukocyte functions. Res Commun Chem Pathol Pharmacol 1992; 78 (2): 151-60.

20. Golub, LM., Ramamurthy, NS., Llavaneras, A., Ryan, ME., Lee, HM., Liu, Y., Bain, S., Sorsa, T. A chemically modified nonantimicrobial tetracycline (CMT-8) inhibits gingival matrix metalloproteinases, periodontal breakdown, and extra-oral bone loss in ovariectomized rats. Ann N Y Acsd Sci 1999; 30: 290-230

21. Paxinos $G$, Watson $C$. The rat brain in stereotaxic coordinates. New York: Academic Press, 1986.

22. Iancu, R., Mohapel, P., Brundin, P., Paul, G. Behavioral characterization of a unilateral 6-OHDA-lesion model of Parkinson's disease. Behav Brain Res 2005; 162: 1-10.

23. Xie, HR., Hu, LS., Li, GY. Human neuroblastoma cell line: In vitro model of dopaminergic neurons in Parkinson's disease. Chin Med J 2010; 123: 1086-1092.

24. Mosmann, T. Rapid colorimetric assay for cellular growth and survival: Application to proliferation and cytotoxicity assays. Journal of Immunological Methods 1983; 65 (1-2): 55-63.

25. Green, LC., Luzuriaga, KR., Wagner, DA., Rand, W., Istfan, N., Young, VR., Tannenbaum, SR. Nitrate biosynthesis in man. Proc. Natl Acad. Sci. 1981; 78 (12): 7764-7768.

26. Lucisano, YM., Mantovani, B. Lysosomal enzyme release from polymorphonuclear leukocytes induced by immune complexes of IgM and of IgG. J Immunol 1984; 132: 2015-20.

27. Saint-Cricq de Gaulejac, NS., Provost, C., Vivas, N. Comparative study of polyphenol scavenging activities assessed by different methods. J Agr and Food Chem 1999; 47: 425-31.

28. Cai, ZY., Yan, Y., Sun, SQ., Zhang, J., Huang, LG., Yan, N., Wu, F., $\mathrm{Li}, J Y$. Minocycline attenuates cognitive impairment and restrains oxidative stress in the hippocampus of rats with chronic cerebral hypoperfusion. Neuroscience Bulletin 2008: 24 (5): 305-313.

29. Matsukawa, N., Yasuhara, T., Hara, K., Xu, L., Maki, M., Yu, G., Kanekol, Y., Ojika, K., Hess, DC., Borlongan, CV. Therapeutic targets and limits of minocycline neuroprotection in experimental ischemic stroke. BMC Neuroscience 2009; 10: 126. 
30. Fan, LW., Lin, S., Pang, Y., Rhodes, PG., Cai, Z. Minocycline attenuates hypoxia-ischemia-induced neurological dysfunction and brain injury in the juvenile rat. Eur J Neurosci 2006; 24: 341 350.

31. Carty, ML., Wixey, JA., Colditz, PB., Buller, KM. Insult minocycline treatment attenuates hypoxia-ischemia-induced neuroinflammation and white matter injury in the neonatal rat: A comparison of two different dose regimens. Int J Dev Neurosci 2008; 26: 477-485

32. Przedborski, S., Tieu, K., Perier, C., Vila, M. MPTP as a mitochondrial neurotoxic model of Parkinson's disease. J Bioenerg Biomembr 2004; 36: 375-379.

33. Quintero, EM., Willis, L., Singleton, R., Harris, N., Huang, P., Bhat, N., Granholm, AC. Behavioral and morphological effects of minocycline in the 6-hydroxydopamine rat model of Parkinson's disease. Brain Res 2006; 1093: 198-207.

34. Rodriguez-Pallares, J., Parga, JA., Muñoz, A., Rey, P., Guerra, MJ., Labrandeira-Garcia, JL. Mechanism of 6-hydroxydopamine neurotoxicity: the role of NADPH oxidase and microglia activation in 6-hydroxydopamine-induced degeneration of dopaminergic neurons. J Neurochem 2007; 103: 145-156.

35. Cohen, G., Heikkila, RE. The generation of hydrogen peroxide, superoxide radical, and hydroxyl radical by 6-hydroxydopamine, dialuric acid, and related cytotoxic agents. J Biol Chem 1974; 249: 2447-2452.

36. Betarbet, R., Sherer, TB., Greenamyre, JT. Animal models of Parkinson's disease. Bioessays 2002; 24: 308-318.

37.Greenamyre, JT., Hastings, TG. Parkinson's- Divergent causes, convergent mechanisms. Science 2004; 304: 1120-1122.

38. Sanchez-Pernate, R., Brownella, AL., Jenkins, BG., Isacsoma, O. Insigths into Parkinson's disease models and neurotoxicity using non-invasive imaging. Toxicology and Applied Pharmacology 2005; 207: 251-256.

39. Blum, D., Torch, S., Lambeng, N., Nisson, M., Benabid, AL., Sadoul, R., Verna, JM. Molecular pathways involved in the neurotoxicity of 6-OHDA, dopamine and MPTP: contribution to the apoptotic theory in Parkinson's disease. Progress in Neurobiology 2001; 65: 135-172.

40. He, Y., Appel, S., Le, W. Minocycline inhibits microglial activation and protects nigral cells after 6- hydroxydopamine injection into mouse striatum. Brain Res 2001; 909: 187-193.

41. Lin, S., Wei, X., Xu, Y., Yan, C., Dodel, R., Zhang, Y. et al. Minocycline blocks 6-hydroxydopamine-induced neurotoxicity and free radical production in rat cerebellar granule neurons. Life Sci 2003; 72 (14): 1635-1641.

42. Du, Y., Ma, Z., Lin, S., Dodel, RC., Gao, F., Bales, KR., Triarhou, LC., Chernet, E., Perry, KW., Nelson, DL., Luecke, S., Phebus, LA., Bymaster, FP., Paul, SM. Minocycline prevents nigrostriatal dopaminergic neurodegeneration in te MPTP model of Parkinson's disease. Proc Nat Acad Sci 2001; 98 (25): 1466914674.
43. Blum, D., Chtarto, A., Tenenbaum, L., Brotchi, J., Levivier, M. Clinical potential of minocycline for neurodegenerative disorders. Neurobiol Dis 2004; 17: 359-366.

44. Tomas-Camardiel, M., Rite, I., Herrera, AJ., de Pablos, RM., Cano, J., Machado, A., Venero, JL. Minocycline reduces the lipopolysaccharide-induced inflammatory reaction, peroxynitrite-mediated nitration of proteins, disruption of the blood-brain barrier, and damage in the nigral dopaminergic system. Neurobiol Dis 2004; 16: 190-201.

45. Amin, AR., Attur, MG., Thakker, GD., Patel, PD., Vyas, PR., Patel, RN., Patel, IR., Abramson, SB. A novel mechanism of action of tetracyclines: Efects on nitric oxide synthases. Proc Natl Acad Sci 1996; 93: 14014-14019.

46. Kraus, RL., Pasiweczny, R., Lariosa-Willingham, K., Turner, MS., Jiang, A., Trauger, JW. Antioxidant properties of minocycline. Neuroprotection in an oxidative stress assay and direct radicalscavenging activity. J Neurochem 2005; 94: 819-827.

47.Schildknecht, S., Pape, R., Müller, N., Robotta, M., Marquard, A., Bürkle, A., Drescher, M., Leist, M. Neuroprotection by minocycline caused by direct and specific scavenging of peroxynitrite. J Biol Chem 2011; 286 (7): 4991-5002.

48. Gonzalez, JC., Egea, J., Godino, MC., Fernandez-Gomez, FJ., Sanchez-Prieto, J., Gandia, L., Garcia, AG., Jordan, J., HernandezGuijo J. Neuroprotectant minocycline depresses glutamatergic neurotransmission and $\mathrm{Ca}^{2+}$ signaling in hippocampal neurons. European Journal of Neurosciene, 2007, 26: 241--2495.

49. Viana, GSB., Tavares, PLF., Xavier, IPP., Holanda, IR., Andrade, GM. Minocycline reverses neurochemical and behavior alterations in the PD model of 6-OHDA-induced striatal lesions in rats. 16th World Congress on Basic and Clinical Pharmacology, Copenhagen, Denmark, 2010.

50. Homsi, S., Piaggio, T., Croci, N., Noble, F., Plotkine, M., Marchand-Leroux, C., Jafarian-Tehrani, O). Blockade of acute microglial activation by minocycline promotes neuroprotection and reduces locomotor hyperactivity after closed head injury in mice: a twelve-week follow-up study. Journal of Neurotrauma 2010; 27: 911-921

51. McCoy, MK., Tansey, 8). TNF signaling inhibition in the CNS: implications for normal brain function and neurodegenerative disease. Journal of Neuroinflammatin. 2008 doi: 10.1186/17422094-5-45.

52. Varani, K., Vincenzi, F., Tosi, A., Gessi, S., Casetta, I., Granieri, G., Fazio, P., Leung, E., MacLennan, S., Granieri, E., Borea, PA. A2A adenosine receptor overexpression and functionality, as well as TNF-alpha levels, correlate with motor symptoms in Parkinson's disease FASEB J. 2010; 24: 587-598.

53. Frankola, KA., Greig, NH., Luo, W., Tweedie D. Targeting TNF-alpha to elucidate and ameliorate neuroinflammation in neurodegenerative diseases. CNS Neurol Disord Drug Targets 2011; 10: 391-403. 
54. Sriram, K., Miller, DB., O'Callaghan JP. Minocycline attenuates microglial activation but fails to mitigate striatal dopaminergic neurotoxicity:Rrole of tumor necrosis factor-alpha. Journal of Neurochemistry 2006; 96: 706-718.

55. Huang, WC., Qiao, Y., Xu, L., Kacimi, R., Sun, X., Giffard, RG., Yenari MA. Direct protection of cultured neurons from ischemia-like injury minocycline. Anatomy \& Cell Biology 2010 Ddoi: 10.5115/acb.2019.43.4.325.

56. Drabeck, T., Janata, A., Wilson, CD., Stezoski, J., JaneskoFeldman, K., Tisherman, SA., Foley, LM., Verrier, JD., Kochanek PM. Minocycline attenuates brain tissuew levels of TNF-alpha produced by neurons after prolonged hypothermic cardiac arrest in rats. Ressuscitation 2014 85: 284-291.

57.Pereira, JB., Junqué, C., Bartrés-Faz, D., Ramirez-Ruiz, B., Marti, MJ., Tolosa E. Regional vulnerability of hippocampal subfields and memory deficits in Parkinso"s disease. Hippocamp 2013: 23: $720-728$.

58. Calabresi, P., Castrioto, A., Di Filippo, M., Picconi B. New experimental and clinical links between the hippocampus and the dopaminergic system in Oarkinso"s disease. Lacet Neurol 2013; 12: 811-821.

59. Carlesimo, GA., Piras, F., Assogna, F., Portiari, FE., Caltagirone, C., Spalleta, G. Hippocampal abnormalities and memory deficits in Paekinson's disease. Neurology 2012; 78: 1939-1945.

60. Cheung, YT., Lau, WK., YU, MS., Lai, CS., Yeung, SC., So, KF., Chang, RC. Effects of all-trans-retinoic acid on human SH-SY5Y neuroblastoma as in vitro model in neurotoxicity research. Neurotoxicology 2009; 30: 127-135.

61. Tiong, CX., Lu, M., Dian, J-S. Protective effect of hydrogen sulphide against 6-OHDA-induced cell injury in SH-SY5Y cells involves PKC/PI3K/Akt pathway. Br J Pharmacol 2010; 161: 467480.

62. Woodgate, A., MacGibbon, G., Walton, M., Dragunow, M. The toxicity of 6-hydroxydopamine on PC12 and P19 cells. Brain Res Mol Brain Res 1999; 69: 84-92.

63. Gomez-Lazaro, M., Bonekamp, NA., Galindo, MF., Jordan, J., Schrader, M. 6-Hydroxydopamine (6-OHDA) induces Drp1dependent mitochondrial fragmentation in SH-SY5Y cells. Free Rad Biol Med 2008; 44: 1960-1969.

64. Lee, SM., Yune, TY., Kim, SJ., Kim, YC., Oh, YJ., Markelonis, GJ., Oh, TH. Minocycline inhibits apoptotic cell death via attenuation of TNF-alpha expression following iNOS/NO induction by lipopolysaccharide in neuron/glia co-cultures. J Neurochem 2004; 91: 568-578

65. Andelid, K., Bake, B., Rak, S., Lindén, A., Rosengren, A., Ekberg-Jansson, A. Myeloperoxidase as a marker of increasing inflammation in smokers without severe airway symptoms. Respir Med 2007; 101: 888-895.

66. Loria, V., Dato, I., Graziani, F., Biasucci, LM. Myeloperoxidase: A new biomarker of inflammation in ischemic heart disease and acute coronary syndromes. Mediadors of Inflammation 2008; doi: 10.1155/2008/135625.

67. Dominguez-Rodriguez, A., Abreu-Gonzalez, P. Current role of myeloperoxidase in routine clinical practice. Expert Rev Cardiovasc Ther 2011; 9: 223-230.
68. McGeer, PL., McGeer, EG. Glial reactions in Parkinson's disease. Mov Disord 2008; 23: 474-483.

69. Morimoto, N., Shimazawa, M., Yamashima, T., Nagai, H., Hara, $\mathrm{H}$. Minocycline inhibits oxidative stress and decreases in vitro and in vivo ischemic neuronal damage. Brain Res 2005; 1044: 8-15.

70. Leite, LM., Carvalho, AGG., Ferreira, PLFT., Pessoa, IX., Gonçalves, DO., Lopes, AA., Góes, JGS., Alves, VCC., Leal, LKAM., Brito, GA., Viana, GSB. Anti inflammatory properties of doxycycline and minocycline in experimental models: an in vivo and in vitro comparative study. Inflammopharmacology 2011; 19: 99-110.

71. Viana, GSB., Carvalho, AGG., Peixoto, AVB., Bezerra, CCB. Minocycline reverses behavior and neurochemical changes in the model of global brain ischemia in rats. 16th World Congress on Basic and Clinical Pharmacology, Copenhagen, Denmark, 2010.

72. Plane, JM., Shen, Y., Pleasure, DE., Deng, W. Prospects for minocycline neuroprotection. Arch Neurol 2010; 67: 14421448.

\section{Comment on this article:}

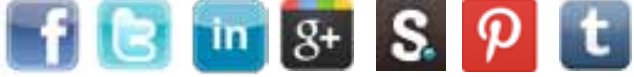

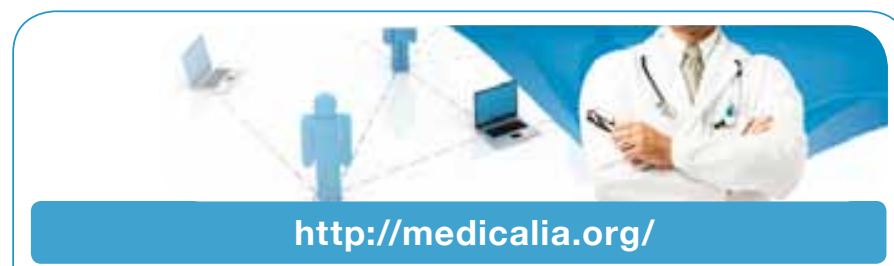

Where Doctors exchange clinical experiences, review their cases and share clinical knowledge. You can also access lots of medical publications for free. Join Now!

\section{Publish with iMedPub \\ http://www.imed.pub}

Neurology and Neuroscience (jneuros.com) is a hybrid, peerreviewed journal that considers articles concerned with any aspect of clinical neurosciences such as neurology, psychiatry and neurosurgery, as well as basic research on neuroscience where neurologists and neuroscientists publish together.

Submit your manuscript here: http://www.jneuros.com 